Research Paper

\title{
The EMSY Gene Collaborates with CCND1 in Non-Small Cell Lung Carcinogenesis
}

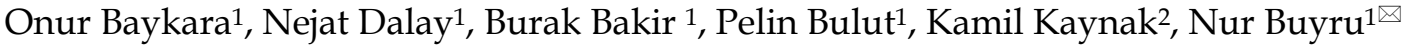 \\ 1. Istanbul University, Department of Medical Biology, Cerrahpasa Medical Faculty, Istanbul 34303, Turkey; \\ 2. Istanbul University, Department of Chest Surgery, Cerrahpasa Medical Faculty, Istanbul 34303, Turkey. \\ $\triangle$ Corresponding author: Prof. Dr. Nur Buyru, Istanbul University, Cerrahpasa Medical Faculty, Dept. Of Medical Biology and Genetics, 34098 \\ Kocamustafapasa, Istanbul, Turkey e-mail: nbuyru@yahoo.com Phone: 905055249471 \\ (c) Ivyspring International Publisher. This is an open access article distributed under the terms of the Creative Commons Attribution (CC BY-NC) license \\ (https://creativecommons.org/licenses/by-nc/4.0/). See http://ivyspring.com/terms for full terms and conditions.
}

Received: 2017.01.26; Accepted: 2017.04.23; Published: 2017.06.23

\begin{abstract}
Background: Lung cancer is the leading cause of cancer deaths. The main risk factor is smoking but the risk is also associated with various genetic and epigenetic components in addition to environmental factors. Increases in the gene copy numbers due to chromosomal amplifications constitute a common mechanism for oncogene activation. A gene-dense region on chromosome $11 \mathrm{q} 13$ which harbors four core regions that are frequently amplified, has been associated with various types of cancer. The important cell cycle regulatory protein cyclin DI (CCNDI) is an essential driver of the first core region of the Chrl lql3 amplicon. Deregulation of CCNDI has been associated with different kinds of human malignancies including lung cancer. The EMSY (cl lorf30) gene has been proposed as the possible driver of the fourth core of the $11 \mathrm{q} 13$ amplicon and its amplification has been associated with breast and ovarian cancers. There is no report in the literature investigating the EMSY gene in lung cancer.

Methods: In this study, expression levels of the EMSY and CCNDI genes were investigated in 85 patients with non small cell lung cancer by Real Time PCR.

Results: Expression of the EMSY and CCNDI genes were increased in 56 (65.8\%) and 50 (58.8\%) of the patients, respectively. Both genes showed a higher expression in the tumors when compared to normal tissues. A strong correlation was present between the expression rates of both genes $(p<0.001)$. Patients with adenocarcinoma had higher expression levels of both genes $(p=0.02)$.

Conclusion: We conclude that EMSY and CCNDI work in collaboration and contribute to the pathogenesis of lung cancer.
\end{abstract}

Key words: CCND1, EMSY, expression, NSCLC.

\section{Introduction}

Lung cancer is the leading cause of death among all types of cancer, both in males and females. Lung cancer is classified into two major classes as non-small cell lung cancer (NSCLC) and small cell lung cancer (SCLC). About $80-85 \%$ of all lung cancer cases are NSCLC whereas SCLC forms the remaining fraction [1]. Epidemiological studies indicate tobacco smoking and alcohol consumption as one of the main causes of lung cancer but approximately $10 \%$ of all cases are never smokers [2, 3]. In addition to smoking, development and progression of lung cancer are under the influence of genetic, epigenetic and environmental factors [4-7].

Chromosomal aberrations include the loss or gains of partial or whole chromosomal arms on several chromosomes and are a hallmark of cancer cells. Increases in the gene copy numbers due to chromosomal amplifications constitute a common mechanism for oncogene activation. Cytogenetic studies using comparative genomic hybridization (CGH) and fluorescence in situ hybridization (FISH) have already associated chromosomal aberrations 
with non-small cell lung cancer (NSCLC) [8, 9]. In particular, oncogene activation through increased gene copy numbers resulting in overexpression contributes to the malignant transformation in various solid tumors, including NSCLC.

Amplification of the $11 \mathrm{q} 13$ region has been frequently detected in different kinds of human malignancies, including lung cancer $[10,11]$. Concurrent or independent amplification of four core regions have been identified within the 11q13 region. One of the key genes driving the amplification of $11 \mathrm{q} 13$ is the cyclin D1 (CCND1) gene [12]. CCND1 is a key regulatory protein that plays an important role in the transition from G1 to the S phase of the cell cycle during cell division. Overexpression of CCND1 results in increased proliferation and disruption of the normal cell cycle [13]. Therefore, CCND1 is considered an essential regulator of the cell cycle. Deregulation of CCND1 has also been implicated in the pathogenesis of lung cancer and is associated with poor prognosis [14].

Chromosome 11q13 is a gene-dense region and in addition to CCND1 several other genes have been implicated in its amplification [15]. Evidence shows that the EMSY gene may be another driver of the $11 q 13$ amplification [16]. EMSY has been identified as a novel BRCA2-interacting protein that is amplified both in breast and ovarian cancers [17]. It has also been reported that the activation or repression function of the BRCA2/EMSY complex may be involved in DNA repair. More recently, Rodriguez et al. reported that EMSY is overexpressed and co-amplified together with CCND1 in patients with sporadic breast cancer [18]. In our previous study, we also observed co-amplification of EMSY and CCND1 genes in 10 of $82(12.2 \%)$ patients with lung cancer [19]. In the literature, most studies have focused on CCND1 in lung cancer in association with 11q13 amplification. There is no report except our previous study investigating the EMSY gene in lung cancer.

Therefore, in this study, considering the contribution of CCND1 and EMSY to the progression of various types of cancer, we investigated the expression levels of both genes in a group of 85 NSCLC tumor samples which have been analyzed for amplification of the 11q13 region.

\section{Methods}

\section{Tissue Samples}

85 patients with NSCLC who underwent surgical resection at the Istanbul University Cerrahpasa Medical Faculty, Department of Chest Surgery were included in the study. Tumor and the adjacent healthy lung tissue samples were obtained during surgery and the specimens were confirmed as tumor and normal samples by a pathologist. The patients taken into the study had not received any previous therapy and were admitted to the hospital for the removal of the tumor as the primary treatment. This study was performed according to the Declaration of Helsinki, 1954 and was approved by the Istanbul Faculty of Medicine Ethics Committee (No.292). Signed informed consent was obtained from all patients.

\section{RT-PCR and Real-Time Quantitative RT-PCR}

Total RNA was isolated from the tumor and normal samples by using the PureLink RNA Mini Kit (Ambion, USA) according to the manufacturer's instructions. cDNAs were synthesized from $400 \mathrm{ng}$ of total RNA using the Transcriptor First Strand cDNA Synthesis Kit (Roche Diagnostics, Mannheim, Germany). Expression levels of the CCND1 and EMSY genes in the tumors and non-cancerous tissue samples were analyzed by Quantitative Real Time PCR (qRT-PCR) using the LightCycler 480 system (Roche Diagnostics, Mannheim, Germany). PCR reactions were performed in a final volume of $20 \mu \mathrm{l}$ containing $1 \times$ Master Mix, $300 \mathrm{nM}$ gene specific primers (forward: 5'-TCAGATGACCCAGGAAAAGAG-3' and reverse: 5'-CTCTGTCCCCTCATCAGTGC-3') and $200 \mathrm{nM}$ hydrolysis probe (UPL Probe No.2) for EMSY and (forward: 5'-GCTGTGCATCTACACCGACA-3' and reverse: 5'-TTGAGCTTGTTCACCAGGAG-3') and $200 \mathrm{nM}$ hydrolysis probe (UPL Probe No.17) for CCND1 which were labeled with fluorescein (FAM) at the 5 '-end and with dark quencher at the 3 '-end. The Glucose-6-Phosphate Dehydrogenase (G6PD) gene was used as the reference to normalize the quantification of mRNA levels. (Primers; forward: 5'CATGGTGCTGAGATTTGCCAAC-3' and reverse: 5'TCAACACCTTGACCTTCTCATCAC-3') probe 5'-FAM-ATCCGGGACGTGATGCAGAACCACCTA C-VIC/HEX Yellow-3'). The $2^{-\Delta \Delta C t}$ method was used to assess the relative mRNA levels [20].

\section{Statistical analysis}

SPSS 21 for Windows (IBM Corp. Released version 2012, IBM SPSS Statistics for Windows, Version 21.0. Armonk, NY: IBM Corp.) was used for statistical analysis. The association between gene expression levels and clinicopathological characteristics were determined by the $x^{2}$ (2-tailed) test. Correlation between the CCND1 and EMSY expression levels was evaluated using the Spearman's rho test.

\section{Results}

In order to investigate the expression rates of the 
EMSY and CCND1 genes which are located on the most frequently amplified 11q13 region in human tumors we analyzed the expression levels of the genes in 85 tumors and matched non-cancerous tissue samples from patients with NSCLC by qRT-PCR. Expression of the EMSY and CCND1 genes were increased in $56(65.8 \%)$ and $50(58.8 \%)$ of the patients, respectively. The mean EMSY and CCND1 mRNA expression levels in tumor tissue were $65 \%$ and $27 \%$ higher than in the corresponding non-cancerous tissue samples, respectively (Table 1). The difference between the expression levels in the tumors and normal tissue was statistically significant $(p<0.001)$. On the other hand, we found a strong correlation between the expression rates of both genes $(p<0.001)$. A total of 65 patients out of 85 showed a concurrent pattern of either up- or down-regulation. An increase in both CCND1 and EMSY expression was observed in $45(52.9 \%)$ patients while $20(23.5 \%)$ tumors had decreased expression of both genes $(p<0.05, r: 0.63)$ (Table 2). When we investigated the correlation between the expression levels and clinicopathological characteristics higher EMSY and CCND1 mRNA levels were observed in patients with adenocarcinomas (Table 3). Of 50 patients with increased CCND1 expression, 26 (52\%) were diagnosed as adenocarcinoma, $17(34 \%)$ as squamous cell carcinoma and $7(14 \%)$ as other pathologies $(\mathrm{p}=0.024)$. Similarly, of 56 patients displaying increased EMSY expression, 28 (50\%) patients had adenocarcinoma, $20(35.7 \%)$ had squamous cell carcinoma and $8(14.3 \%)$ patients had other pathologies $(p=0.026)$. However, no statistically significant correlation was found between the expression levels of both genes and other clinicopathologic characteristics $(\mathrm{p} \geq 0.05)$.

Table 1. Mean Ct values of EMSY and CCNDI genes compared to normalized values with G6PD gene in cancerous and non-cancerous tissue samples.

\begin{tabular}{llllll}
\hline & $\begin{array}{l}\text { EMSY Ct } \\
\text { (Mean) }\end{array}$ & $\begin{array}{l}\text { G6PD Ct } \\
\text { (Mean) }\end{array}$ & $\boldsymbol{\Delta C t}$ & $\boldsymbol{\Delta} \mathbf{\Delta C t}$ & 2- $\Delta \Delta \mathrm{Ct}$ \\
\hline Tumor & 28.97 & 27.49 & 1.48 & -0.71 & 1.64 \\
Normal & 30.93 & 28.74 & 2.19 & - & - \\
& $\begin{array}{l}\text { CCND1 Ct } \\
\text { (Mean) }\end{array}$ & $\begin{array}{l}\text { G6PD Ct } \\
\text { (Mean) }\end{array}$ & & & \\
Tumor & 26.31 & 27.29 & -0.98 & -0.35 & 1.27 \\
Normal & 29.12 & 29.75 & -0.63 & - & - \\
\hline
\end{tabular}

Table 2. Values of the patients showing concurrent pattern of either up- or down-regulation.

\begin{tabular}{|c|c|c|c|c|c|}
\hline & & CCND & & & \\
\hline \multirow{4}{*}{ EMSY } & & $\begin{array}{l}\text { Increase } \\
\mathrm{n}(\%)\end{array}$ & $\begin{array}{l}\text { No-change } \\
\mathrm{n}(\%)\end{array}$ & $\begin{array}{l}\text { Decrease } \\
\mathrm{n}(\%)\end{array}$ & $p$ \\
\hline & Increase & $45(52.9)$ & $3(3.5)$ & $8(9.4)$ & \\
\hline & No-change & $1(1.2)$ & $1(1.2)$ & $0(0)$ & $<0.001$ \\
\hline & Decrease & $4(4.7)$ & $0(0)$ & $20(23.5)$ & \\
\hline
\end{tabular}

Table 3. Clinicopathologic characteristics of the patients and their distribution in relevance with EMSY and CCNDI expression.

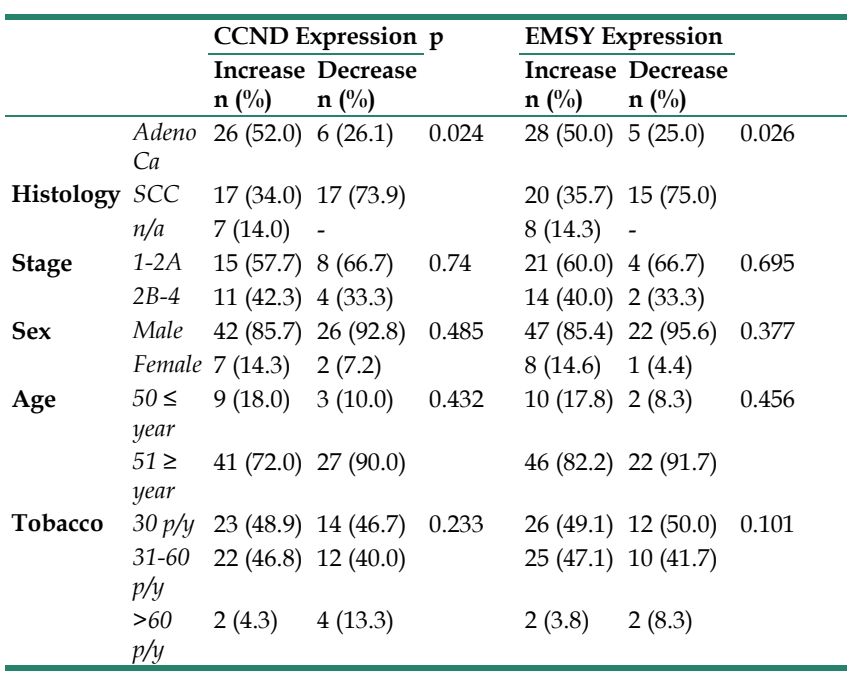

\section{Discussion}

The chromosomal 11q13 locus is one of the frequently amplified chromosomal regions in different kinds of human cancers including lung cancer [10]. Several studies have provided experimental evidence that the 11q13 amplicon is complex and displays multiple cores potentially harboring distinct drivers [21-23]. While the CCND1, CTTN (EMS1) and GAB2 genes have long been considered as potential drivers of the second core, identification of a novel gene, EMSY has suggested that it is the driver of the third core [17]. On the other hand, the CCND1 gene is involved in approximately two thirds of all 11q13 amplicons [24]. Despite reports on over-expression of different genes in that region, the most likely tumorigenic driver at this locus is still thought to be CCND1, which encodes cyclin D1 [25]. Cyclin D1 is a key regulatory protein that plays an important role in the transition from G1 to the S phase of the cell cycle and increases in the CCND1 copy number have been reported in different kinds of cancer including in breast, esophageal or laryngeal cancers and NSCLC $[13,25]$. In our previous study we also observed CCND1 amplification in $12.2 \%$ of the NSCLC tumor samples [19]. However, in our study group we did not observe an association between the increase in copy numbers and expression of the CCND1 mRNA as reported by Dragoj et al. [26]. In NSCLC tumors overexpression of CCND1 was more frequent than copy number variations. Our data indicate that overexpression of the CCND1 gene can occur independent of gene amplification.

In 2003, EMSY has been identified as a BRCA2-binding and inactivating protein by Hughes-Davies et al. [17]. However, its exact mechanism of action has not been investigated in 
detail. In recent years more detailed and comprehensive research has aimed to identify the protein partners of EMSY. As a result of these experimental and in silico studies it has been suggested that EMSY may function in DNA damage repair, chromatin remodeling and regulation of transcription [17, 27-29]. It has also been reported that EMSY was amplified in $13 \%$ of sporadic breast cancers, $17 \%$ of high grade ovarian cancers and $13 \%$ of sporadic pancreatic adenocarcinomas [16-18, 30, 31]. As to our knowledge, there is no data in the literature except a single study investigating the EMSY gene in NSCLC. In this study, Wilkerson et al. [32] have analyzed amplification of the EMSY gene in 10 different cancer cell lines from different anatomical sites. As a result of this study they observed EMSY amplification in the NCI-H1395 stage 2 lung cancer cell line. In our previous study we observed a similar frequency of EMSY amplification in tumors from patients with NSCLC [19]. In some studies EMSY amplification has been associated with increased levels of mRNA $[16,18]$. When we investigated EMSY expression levels we observed a higher overexpression rate in the tumor samples than the corresponding increase in the copy numbers or amplification. Another interesting point was the concurrent overexpression of EMSY with CCND1 in our study group. It is well known that CCND1 does not exert its tumorigenic activity by itself [26]. This statistically significant association between the overexpression of the CCND1 and EMSY genes in NSCLC indicates that two genes of the chromosome 11q13 amplification region cooperate in lung carcinogenesis. We also detected a significant correlation between overexpression of the EMSY and CCND1 genes and the histologic type. Overexpression of both genes were associated with adenocarcinoma of the lung. In accordance with overexpression of CCND1 in our study group most recently Dragoj et al. [26] also reported overexpression of CCND1 in the adenocarcinoma subtype. On the other hand, our results also support the data reported by Wilkerson et al. [32] who have observed EMSY overexpression in the stage 2 lung adenocarcinoma cell line.

We conclude that EMSY as a frequently amplified chromosome 11q13 region gene contributes to the progression of NSCLC in collaboration with CCND1. Therefore, the mechanism of the action of the EMSY gene in NSCLC warrants more detailed studies. Identifying its partners and investigation of the mutual interactions would help for the determination of new prognostic and predictive markers in NSCLC.

\section{Acknowledgement}

This study was funded by The Scientific and Technological Research Council of Turkey (TUBITAK). Project no: 114Z489

\section{Competing Interests}

The authors have declared that no competing interest exists.

\section{References}

1. Siegel RL, Miller KD, Jemal A. Cancer statistics, 2015. CA Cancer J Clin. 2015; 65: 5-29.

2. Hecht SS. Tobacco smoke carcinogens and lung cancer. J Natl Cancer Inst. 1999; 91: 1194-210.

3. Couraud S, Zalcman G, Milleron B, Morin F, Souquet PJ. Lung cancer in never smokers--a review. Eur J Cancer. 2012; 48: 1299-311.

4. Hung RJ, McKay JD, Gaborieau V, Boffetta P, Hashibe M, Zaridze D, et al. A susceptibility locus for lung cancer maps to nicotinic acetylcholine receptor subunit genes on 15q25. Nature. 2008; 452: 633-7.

5. Sellers TA, Bailey-Wilson JE, Elston RC, Wilson AF, Elston GZ, Ooi WL, et al. Evidence for mendelian inheritance in the pathogenesis of lung cancer. J Natl Cancer Inst. 1990; 82: 1272-9.

6. Sellers TA, Weaver TW, Phillips B, Altmann M, Rich SS. Environmental factors can confound identification of a major gene effect: results from a segregation analysis of a simulated population of lung cancer families. Genet Epidemiol. 1998; 15: 251-62

7. Ramalingam SS, Owonikoko TK, Khuri FR. Lung cancer: New biological insights and recent therapeutic advances. CA Cancer J Clin. 2011; 61: 91-112.

8. Berrieman HK, Ashman JN, Cowen ME, Greenman J, Lind MJ, Cawkwell L. Chromosomal analysis of non-small-cell lung cancer by multicolour fluorescent in situ hybridisation. Br J Cancer. 2004; 90: 900-5.

9. Luk C, Tsao MS, Bayani J, Shepherd F, Squire JA. Molecular cytogenetic analysis of non-small cell lung carcinoma by spectral karyotyping and comparative genomic hybridization. Cancer Genet Cytogenet. 2001; 125: 87-99.

10. Schwab M. Amplification of oncogenes in human cancer cells. Bioessays. 1998; 20: 473-9.

11. Xu J, Tyan T, Cedrone E, Savaraj N, Wang N. Detection of 11q13 amplification as the origin of a homogeneously staining region in small cell lung cancer by chromosome microdissection. Genes Chromosomes Cancer. 1996; 17: 172-8.

12. Gautschi O, Ratschiller D, Gugger M, Betticher DC, Heighway J. Cyclin D1 in non-small cell lung cancer: a key driver of malignant transformation. Lung Cancer. 2007; 55: 1-14.

13. Knudsen KE, Diehl JA, Haiman CA, Knudsen ES. Cyclin D1: polymorphism, aberrant splicing and cancer risk. Oncogene. 2006; 25: 1620-8.

14. Brennan P, Hainaut P, Boffetta P. Genetics of lung-cancer susceptibility. Lancet Oncol. 2011; 12: 399-408.

15. Gibcus JH, Kok K, Menkema L, Hermsen MA, Mastik M, Kluin PM, et al. High-resolution mapping identifies a commonly amplified 11q13.3 region containing multiple genes flanked by segmental duplications. Hum Genet. 2007; 121: 187-201.

16. Brown LA, Irving $\mathrm{J}$, Parker $\mathrm{R}$, Kim $\mathrm{H}$, Press $\mathrm{JZ}$, Longacre $\mathrm{TA}$, et al. Amplification of EMSY, a novel oncogene on 11q13, in high grade ovarian surface epithelial carcinomas. Gynecol Oncol. 2006; 100: 264-70.

17. Hughes-Davies L, Huntsman D, Ruas M, Fuks F, Bye J, Chin SF, et al. EMSY links the BRCA2 pathway to sporadic breast and ovarian cancer. Cell. 2003; 115: 523-35

18. Rodriguez C, Hughes-Davies L, Vallès H, Orsetti B, Cuny M, Ursule L, et al. Amplification of the BRCA2 pathway gene EMSY in sporadic breast cancer is related to negative outcome. Clin Cancer Res. 2004; 10: 5785-91.

19. Baykara O, Bakir B, Buyru N, Kaynak K, Dalay N. Amplification of chromosome 8 genes in lung cancer. J Cancer. 2015; 6: 270-5.

20. Livak KJ, Schmittgen TD. Analysis of relative gene expression data using real-time quantitative PCR and the 2(-Delta Delta C(T)) Method. Methods. 2001; 25: 402-8.

21. Bocanegra M, Bergamaschi A, Kim YH, Miller MA, Rajput AB, Kao J. Focal amplification and oncogene dependency of GAB2 in breast cancer. Oncogene. 2010; 29: 774-9.

22. Elsheikh S, Green AR, Aleskandarany MA, Grainge M, Paish CE, Lambros MB, et al. CCND1 amplification and cyclin D1 expression in breast cancer and their relation with proteomic subgroups and patient outcome. Breast Cancer Res Treat. 2008; 109: 325-35.

23. Dedes KJ, Lopez-Garcia MA, Geyer FC, Lambros MB, Savage K, Vatcheva R. Cortactin gene amplification and expression in breast cancer: a chromogenic in situ hybridisation and immunohistochemical study. Breast Cancer Res Treat. 2010; 124: 653-66.

24. Vaziri SA, Tubbs RR, Darlington G, Casey G. Absence of CCND1 gene amplification in breast tumours of BRCA1 mutation carriers. Mol Pathol. 2001; 54: 259-63. 
25. Musgrove EA, Caldon CE, Barraclough J, Stone A, Sutherland RL. Cyclin D as a therapeutic target in cancer. Nat Rev Cancer. 2011; 11: 558-72.

26. Dragoj M, Milosevic Z, Bankovic J, Dinic J, Pesic M, Tanic N, et al. Association of CCND1 overexpression with KRAS and PTEN alterations in specific subtypes of non-small cell lung carcinoma and its influence on patients' outcome. Tumour Biol. 2015; 36: 8773-8880.

27. Ekblad CM, Chavali GB, Basu BP, Freund SM, Veprintsev D, Hughes-Davies L, et al. Binding of EMSY to HP1beta: implications for recruitment of HP1beta and BS69. EMBO Rep. 2005; 6: 675-80.

28. Chavali GB, Ekblad CM, Basu BP, Brissett NC, Veprintsev D, Hughes-Davies L, et al. Crystal structure of the ENT domain of human EMSY. J Mol Biol. 2005; 350: 964-73.

29. Garapaty S, Xu CF, Trojer P, Mahajan MA, Neubert TA, Samuels HH. Identification and characterization of a novel nuclear protein complex involved in nuclear hormone receptor-mediated gene regulation. J Biol Chem. 2009; 284: 7542-52.

30. van Hattem WA, Carvalho R, Li A, Offerhaus GJ, Goggins M. Amplification of EMSY gene in a subset of sporadic pancreatic adenocarcinomas. Int J Clin Exp Pathol. 2008; 1: 343-51.

31. Altinisik J, Karateke A, Coksuer H, Ulutin T, Buyru N. Expression of EMSY gene in sporadic ovarian cancer. Mol Biol Rep. 2011; 38: 359-63.

32. Wilkerson PM, Dedes KJ, Wetterskog D, Mackay A, Lambros MB, Mansour M, et al. Functional characterization of EMSY gene amplification in human cancers. J Pathol. 2011; 225: 29-42. 